\title{
Microwave Synthesis and Antimicrobial Activity of Some Copper (II), Cobalt (II), Nickel (II) and Chromium (III) Complexes with Schiff Base 2, 6-pyridinedicarboxaldehyde- Thiosemicarbazone
}

\author{
MOHAMMED FAKRUDDIN ALI AHMED ${ }^{1}$ and V. MAHAMMADYUNUS \\ 1Department of Chemistry, College of Natural Science, Jimma University, Post-Box No:378, Ethiopia. \\ ${ }^{\star}$ Corresponding author E-mail: mfaahamed@gmail.com \\ http://dx.doi.org/10.13005/ojc/300114
}

(Received: January 10, 2014; Accepted: February 06, 2014)

\begin{abstract}
Some novel Schiff base metal complexes of $\mathrm{Cr}(\mathrm{III}), \mathrm{Co}(\mathrm{II}), \mathrm{Ni}(\mathrm{II})$ and $\mathrm{Cu}(\mathrm{II})$ derived from 2 , 6-pyridinedicarboxaldehyde-Thiosemicarbazone (PDCTC) was synthesized by conventional as well as microwave methods. This compound was characterized by elemental analysis, FT-IR, Mass, molar conductance and magnetic susceptibility measurements analyses. Analytical data revealed that all the complexes exhibited 1:1 (metal: ligand) ratio with a coordination number of six. The IR data showed that the ligand coordinates with the metal ions in ahexa-dentate manner. The solid state electrical conductivity of the metal complexes was also measured. Solid state electrical conductivity studies reflected a semi-conducting nature of the complexes. The Schiff base and metal complexes displayed good activity against the Gram-positive bacteria Staphylococcus aureus, the Gram-negative bacteria Escherichia coli and the fungi Aspergillusniger and Candida albicans. The antimicrobial results also indicated that the metal complexes displayed better antimicrobial activity as compared to the Schiff bases.
\end{abstract}

Key words: Microwave method; Hexa-dentate ligands; Biological activities.

\section{INTRODUCTION}

Microwave irradiation now a day is an accepted tool for accelerating the organic and inorganic reactions. It leads to the higher reaction selectivity and utilization of the inexpensive reagents. In addition to providing an eco-friendly "green chemistry" approach to the reaction, it is free of environmental impacts ${ }^{1-5}$. The application of microwave irradiation towards the acceleration of wide range of organic and inorganic reactions has received concealable attention ${ }^{6-11}$. It also allowed a greener approach ${ }^{12}$.

Schiff base of an important class of ligands in coordination chemistry and have many applications ${ }^{13}$, in different fields. The chemistry of Schiff base complexes continues to attract many researchers ${ }^{14-16}$ because of their wide application in food industry, dye industry , analytical chemistry 
catalysis, antimicrobial activity, agro-chemical activity ${ }^{17}$ and pharmacological applications ${ }^{18}$. Semicabazones of aromatic and unsaturated carbonyl compounds have anticonvulsant properties and their advantage over the analogous Thiosemicarbazone is their lesser neurotoxicity ${ }^{19}$. Semicabazones have an inhibitory effect on nitric oxide synthesis, which protect the vascular system ${ }^{20}$.

It is well known that various organic ligands possess strong antibacterial, herbicidal, insecticidal and fungicidal properties ${ }^{21}$. It has also been reported that the activity of bio metals is very often altered through the formation of chelates with different biological relevant ligands ${ }^{22-25}$. It is suggest that the compounds having antimicrobial activity may act either by killing the microbe or blocking their active sites $^{26-28}$. In addition to this the antimicrobial activity of the compounds also depends upon the nature of the microorganisms.

\section{MATERIALS AND METHODS}

All the chemicals used were of AR grade and used without further purification. The infrared<smiles></smiles>

Fig. 1: Structure of Ligand - (PDCTC) spectra were recorded in the range $4000-180 \mathrm{~cm}^{-1}$ with a Perkin Elmer 983 G spectrophotometer. The electronic spectra were recorded with Cary model 2390 spectrometer. The molar conductance of complexes in DMF ( 10-3 M) was determined at $27 \pm 20^{\circ} \mathrm{C}$ using a Systronic 303 direct reading conductivity bridge. The magnetic susceptibility measurements were made using a vibrating sample magnetometer (VSM) operating at field strength of 5 $\mathrm{KG}$. The ${ }^{1} \mathrm{H}$ NMR spectra was recorded on varian $\mathrm{XL}$ $300 \mathrm{MHz}$ high resolution instrument in $\mathrm{CDCl}_{3}$ solvent. The mass spectra were recorded using Fanning Mat 8230 Mass spectrometer.

Microwave assisted synthesis were carried out in open glass vessel on a modified microwave oven model 2001 ETB with rotating tray and a power source $230 \mathrm{~V}$, microwave energy output $800 \mathrm{~W}$ and microwave frequency $2450 \mathrm{MHz}$. A thermocouple device was used to monitor the temperature inside the vessel of the microwave. The microwave reactions were performed using on/off cycling to control the temperature.

\section{Conventional method for the synthesis of Schiff bases}

The reaction mixture containing 2 , 6-Pyridinedicarboxaldehyde, (2g, 0.01183mol in $20 \mathrm{ml}$ of methanol) Thiosemicarbazone $(1.0787 \mathrm{~g}$, .0 .01183 mole in $20 \mathrm{ml}$ of methanol dissolved in hot condition) was taken in250-ml round bottom flask and refluxed for $10 \mathrm{~h}$. On cooling the reaction mixture, light yellow coloredproduct was formed. It was collected by filtration and washed with hot water and $50 \%$ cold methanol. This compound was recrystallized from ethanol and dried in vacuo, yield $65 \%$; m. p. $257^{\circ} \mathrm{C}$. (Fig. 2)<smiles>NC(=S)NNC(=S)/N=C/c1cccc(/C=N/NC(=S)N/N=C/c2cccc(C=O)n2)n1</smiles>

Fig. 2: Preparation ofLigand -PDCTC 
Microwave method for the synthesis of Schiff bases

The equimolar (1:1) ratio of methyl isobutyl ketone with 2, 6-Pyridinedicarboxaldehyde, and Thiosemicarbazone with isonicotinic acid hydrazide were mixed thoroughly in agrinder. The reaction mixture was then irradiated by the microwave oven by taking $3-4 \mathrm{~mL}$ of dry ethanol as a solvent. The reaction was completed in a short time (4-5min) with higher (light yellow) yields. The resulting product was then recrystallized with ethanol, finally dried under reduced pressure over anhydrous $\mathrm{CaCl}_{2}$ in a desiccator. The progress of the reaction, purity of the product was monitored by TLC using silica gel G (yield: 85\%).

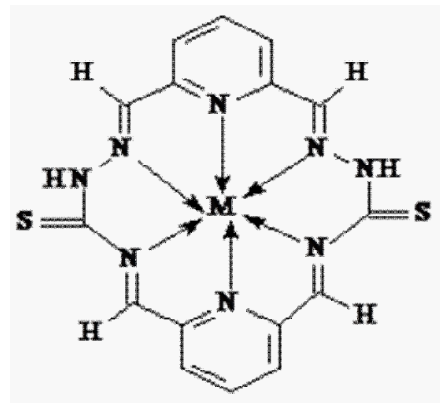

Fig. 3: Proposed Structure of Ligand-Metal complexes $\mathrm{M}=\mathrm{Cu}^{2+}, \mathrm{Co}^{2+}, \mathrm{Ni}^{2+}, \mathrm{Cr}^{3+}$

Conventional method for the synthesis of metal complexes

The metal complexes (Figs. 3) was prepared by the mixing of equal moles of metal salts dissolved in the methanol was added followed by $1 \mathrm{ml}$ of $1 \mathrm{M} \mathrm{NaOAc}$ was added, in 1:1 (metal: ligand) ratio. The resulting mixture was refluxed on water bath for 6- 8h. A coloured product appeared on standing and cooling the above solution. The precipitated complex was, filtered washed with ether and recrystallized with ethanol several times and dried under the reduced pressure over anhydrous $\mathrm{CaCl} 2$ in a desiccator. It was further dried in electric oven at $50-70^{\circ} \mathrm{C}$ (yield: $65-70 \%$ ).

Microwave method for the synthesis of metal complexes

The ligand and the metal salts was mixed in 1:1 (metal: ligand) ratio in a grinder. The reaction mixture was then irradiated by the microwave oven by taking $3-4 \mathrm{~mL}$ of dry ethanol as a solvent. The reaction was completed in a short time (5-9min)

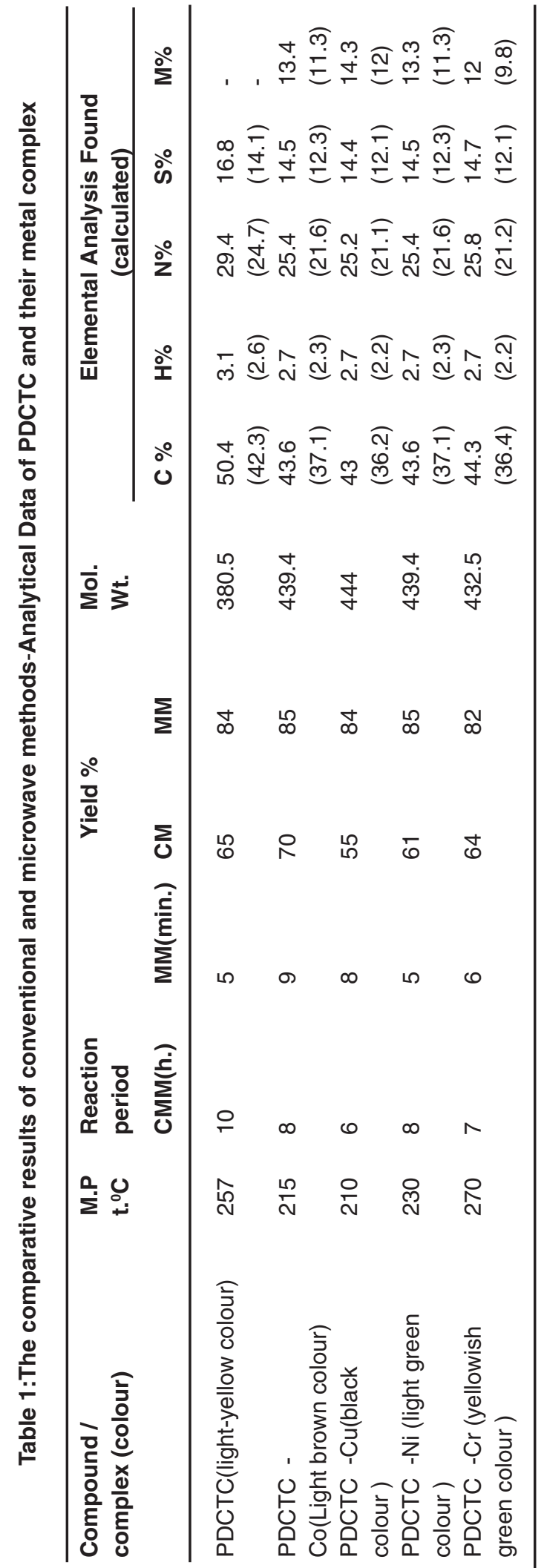


with higher yields. The resulting product was then recrystallized with ethanol and ether and finally dried under reduced pressure over anhydrous $\mathrm{CaCl} 2$ in a desiccator. The progress of the reaction and purity of the product was monitored by TLC using silica gel G (yield: 80-85\%).

\section{RESULTS AND DISCUSSION}

The analytical data for all the complexes are given in Table-1. The molar conductivity data(Table-3) of the complexes are consistent with the nonelectrolytic nature ${ }^{30-31}$ of the complexes. The ligand and complexes were characterized by elemental analysis to determine percentage of $\mathrm{C}, \mathrm{N}, \mathrm{S}$ and $\mathrm{H}$. The observed and calculated percentages of the elements are in good agreement and support one ligand to a metal ion. The number of coordinated ligands to metal determined by Job's continuous method and Mole ratio method established 1: 1 metal to ligand ratio.

\section{IR and ${ }^{1} \mathrm{H}$ NMR Spectral Analysis}

The reagents have been characterized by $\mathrm{IR}$ and ${ }^{1} \mathrm{H}$ NMR spectral data. The infrared spectra of PDCTC show bands at $1697 \mathrm{~cm}^{-1}$ for $\mathrm{vC}=\mathrm{N} ; 722$ for $\mathrm{vC}-\mathrm{S}$; 1540 for $\mathrm{vC}=\mathrm{S}$; indicating the Schiff base formation. The lowering of $\mathrm{vC}=\mathrm{N}$ of azomethine group to the extent of $30-50 \mathrm{~cm}^{-1}$ in all the complexes suggests the participation ${ }^{27-29}$ of azomethine nitrogen in complexation. On coordination, this band is shifted to lower frequency suggests that the ligand is coordinated to metal ion via azomethine nitrogen in all complexes. This change in shift is due to the drift of the lone pair density of azomethine nitrogen towards metal atom ${ }^{32}$. In the far IR spectral region,

Table 2: Selected IR bands $\left(\mathrm{cm}^{-1}\right)$ with tentative assignments

\begin{tabular}{lccccc}
\hline Compound & $v \mathbf{C}=\mathbf{N}$ & $v \mathbf{C}-\mathbf{S}$ & $v \mathbf{C}=\mathbf{S}$ & $v \mathbf{M}-\mathbf{N}$ & $v \mathbf{M}-\mathbf{S}$ \\
\hline PDCTC & 1697 & 722 & 1540 & - & - \\
Cu-PDCTC & 1615 & 650 & 1560 & 420 & 355 \\
Co- PDCTC & 1608 & 708 & 1550 & 415 & 352 \\
Ni- PDCTC & 1610 & 707 & 1540 & 412 & 340 \\
Cr- PDCTC & 1623 & 712 & 1545 & 405 & 325 \\
\hline
\end{tabular}

Table 3: Molar conductance data of metal complexes ofPDCTC

\begin{tabular}{lc}
\hline PDCTC - Complex & $\begin{array}{c}\text { Conductance } \\
\left(\mathrm{Ohm}^{-1} \mathrm{Cm}^{2} \mathrm{~mol}^{-1}\right)\end{array}$
\end{tabular}

\begin{tabular}{ll}
\hline Cu-PDCTC & 26 \\
Co- PDCTC & 24 \\
Ni- PDCTC & 22 \\
Cr- PDCTC & 36 \\
\hline
\end{tabular}

additional medium to strong bands at 405-420 and $325-355 \mathrm{~cm}^{-1}$ are assigned to $v \mathrm{M}-\mathrm{N}$ and $v M-S$ modes $(31,32)$ respectively. ${ }^{1} \mathrm{H}$ NMRspectra of PDCTC $\left(\mathrm{CDCl}_{3}+\mathrm{DMSO}_{-} \mathrm{d}_{6}\right)$ showed signals at 2.27, $(1 \mathrm{H}, \mathrm{s})$; 8.15-8.32 $\left({ }^{1} \mathrm{H}\right), 7.10,7.86(4 \mathrm{H}, \mathrm{s}) 3.25\left({ }^{1} \mathrm{Hs}\right)$ due to $\mathrm{C}=\mathrm{N}\left(\mathrm{C}_{5} \mathrm{H}_{4} \mathrm{~N}\right), \mathrm{NH}$.

The magnetic moment (Table-4) value of Cu-PDCTC was 2.24 BM indicates one electron
Table 4: Molar conductance data of metal complexes ofPDCTC

\begin{tabular}{lc}
\hline PDCTC - Complex & $\begin{array}{c}\text { Magnetic Momentum } \\
\text { (B.M) }\end{array}$ \\
\hline Cu- PDCTC & 2.24 \\
Co- PDCTC & 2.05 \\
Ni- PDCTC & 3.73 \\
Cr- PDCTC & 2.12 \\
\hline
\end{tabular}

paramagnetism. This value is higher than the spinonly value of $1.73 \mathrm{BM}$ for one unpaired electron. The higher value of the magnetic moment indicates that complexes are monomeric in nature and there is no metal-metal interaction along the axial position in the complex and have distorted octahedral environment ${ }^{35-}$ 37. The magnetic moment of Co-PDCTC was found to lie in 2.05 BM. Monomeric cobalt complexes have lower magnetic moment values than would be 
expected for pure octahedral complexes suggesting flattening towards planar arrangement ${ }^{38-42}$. The magnetic moments of $\mathrm{Ni}$ (II) complex was observed at 3.73 $\mathrm{BM}$. This value is in the range reported earlier for octahedral complexes ${ }^{43}$. $\mathrm{Cr}$ (III) complexwas observed at 2.12 BM.

\section{Antimicrobial activities}

The in-vitro Antimicrobial activity of the synthesized Schiff base ligands and their corresponding metal complexes on selected bacteria $E$. coli and $S$. aureusand two fungi $A$. niger and $C$. albicans was carried out. All of the tested compounds showed good biological activity against microorganism. On comparing the biological activity of the Schiff base and its metal complexes with the standard bactericide and fungicide, it is show that the some metal complexes have good activity as compared to the standard but all the complexes are more active than their respective ligands. The higher inhibition zone of metal complexes than those of the ligands can be explained on the basis of Overtone's concept and Chelation theory. On chelation, the polarity of the metal ion will be reduced to greater extent due to the overlap of the ligand orbital and partial sharing of the positive charge of the metal ion with donor groups. Further, it increases the delocalization of À-electrons over the whole chelating ring and enhances the penetration of the complexes into lipid membranes and blocking of the metal binding sites in the enzymes of microorganisms. There are other factors which also increase the activity are solubility, conductivity and bond length between the metal and ligand ${ }^{44-47}$.The bactericidal and fungicidal investigation data of the compounds are summarized in Tables 5 and 6 . The results of

Table 5: Antibacterial screening data for the ligands and their complexes

\begin{tabular}{|c|c|c|c|c|c|c|c|c|c|c|c|c|}
\hline \multirow[t]{3}{*}{ Compound } & \multicolumn{6}{|c|}{ E.coli } & \multicolumn{6}{|c|}{ S. aures } \\
\hline & \multicolumn{3}{|c|}{$\begin{array}{r}\text { Diameter of } \\
\text { inhibition } \\
\text { zone }(\mathrm{mm})\end{array}$} & \multicolumn{3}{|c|}{$\begin{array}{c}\% \text { Activity } \\
\text { index }\end{array}$} & \multicolumn{3}{|c|}{$\begin{array}{l}\text { Diameter of } \\
\text { inhibition } \\
\text { zone }(\mathrm{mm})\end{array}$} & \multicolumn{3}{|c|}{$\begin{array}{l}\% \text { Activity } \\
\text { index }\end{array}$} \\
\hline & 25 & 50 & 100 & 25 & 50 & 100 & 25 & 50 & 100 & 25 & 50 & 100 \\
\hline PDCTC & 10 & 15 & 18 & 45 & 60 & 62 & 12 & 16 & 19 & 63 & 64 & 76 \\
\hline Cu-PDCTC & 13 & 16 & 20 & 59 & 64 & 68 & 13 & 15 & 20 & 68 & 71 & 80 \\
\hline Co-PDCTC & 14 & 17 & 21 & 63 & 68 & 72 & 12 & 14 & 18 & 63 & 66 & 72 \\
\hline Ni-PDCTC & 16 & 19 & 23 & 72 & 76 & 79 & 11 & 15 & 18 & 57 & 71 & 72 \\
\hline Cr-PDCTC & 17 & 20 & 24 & 77 & 80 & 82 & 10 & 16 & 20 & 52 & 76 & 80 \\
\hline $\begin{array}{l}\text { Streptomycin } \\
\text { (Standard) }\end{array}$ & 22 & 25 & 29 & 100 & 100 & 100 & 19 & 21 & 25 & 100 & 100 & 100 \\
\hline
\end{tabular}

Table 6: Antifungal screening data for the ligands and their complexes

\begin{tabular}{|c|c|c|c|c|c|c|}
\hline \multirow[t]{3}{*}{ Compound } & \multicolumn{6}{|c|}{ Diameter of inhibition zone $(\mathrm{mm})$; Concentration in ppm } \\
\hline & \multicolumn{3}{|c|}{ A.nizer } & \multicolumn{3}{|c|}{ C.albicans } \\
\hline & 25 & 50 & 100 & 25 & 50 & 100 \\
\hline PDCTC & 12 & 15 & 21 & 13 & 16 & 20 \\
\hline Cu-PDCTC & 14 & 18 & 23 & 14 & 19 & 24 \\
\hline Co-PDCTC & 15 & 20 & 24 & 15 & 18 & 22 \\
\hline Ni-PDCTC & 16 & 19 & 23 & 14 & 17 & 21 \\
\hline Cr-PDCTC & 15 & 21 & 25 & 18 & 20 & 25 \\
\hline Miconazole (Standard) & 22 & 25 & 32 & 24 & 26 & 30 \\
\hline
\end{tabular}


the investigations account for the anti-pathogenic behavior of the compounds and this efficacy is positively modified on complexation.

$\%$ Activity index $=\frac{\text { Zone of inhibition by test compound (diameter) }}{Z \text { one of inhibition by test standard (diameter) }}+100$

\section{CONCLUSION}

In the present research studies, our successful efforts are synthesis of some newly compounds from the conventional as well as microwave methods. These synthesized compounds have been characterized by various physicochemical,VSM and spectral analyses. In the result of microwave-assisted synthesis, it has been observed that the reaction time decreased from hours to minutes and availability of the product within better yields compared to the classical method. Electrical conductivity data suggest that all the complexes fall in the semiconducting range. The antimicrobial data show that the metal complexes to be more biological active compared to those parent Schiff base ligand against all pathogenic species. The compounds also inhibit the growth of fungi and bacteria to a greater extent as the concentration is increased. The Schiff base ligands were found to be biologically active and their metal complexes displayed enhanced antimicrobial activity against one or two strains. Chelation tends to make the ligand act as more powerful and potent bactericidal agent. Further chelation can help in MDR problems.

\section{REFERENCES}

1. Ashry,E S H E1,Ramadan E,Kassem E, Kassem A A and Hager M,Adv Heterocycl Chem, 68: 1 (2005).

2. Kappe C O\&Loupy A ,Microwave in Organic Synthesis (WileyVCH,Weinheim),2002,pp405.

3. Kappe C O,Curr Opinion Chem Bio, 6: 314 (2002).

4. Danida A, Arya K, Sati M \&Gautam S, Tetrahedron, 60: 5253 (2004).

5. K. Sapna, N. Kumar Sharma and S. Kohli, Orient J. Chem., 28(2): 969-974 (2012).

6. Gedye R, Smith F,Westaway K, Ali H, Baldisera L, Laberge L \&Rousell J, Tetrahedron Lett., 27: 279 (1986).

7. Gedye R J, Bray T L \& Duncan S M, Tetrahedron Lett., 27: 2945 (1986).

8. Caddick S,TetrahedronLett., 50: 10403 (1994).

9. Mingos D M P \&Baghurst D R, Chem Rev, 20: 1 (1991).

10. Whittaker A G \&Mingos D M P,J Microwave Power Electomag Energy, 29: 195 (1994).

11. Mingos D M P, Res Chem Intermid, 20: 85 (1994).

12. Whittaker A G, Educ Chem, 134 (2002).

13. Suma S, Kumar M R S,Nair C R \&Prabhakaran C P, Indian J Chem, 32A: 214 (1993).

14. Warad D U, Salish C D, Kulkarani V H \&Bajgur C S,Indian J Chem,39A: 415 (2000).
15. Sen A K, Singh G, Singh K, Noren R K, Handa R N \&Dubey S N, Indian J Chem, 36A: 891 (1997).

16. S. Kumar, S. Yadav, S. Jadon, V. Kumar, A.M. Kheder and Krishan C. Gupta, Orient J. Chem., 28(4): 1833-1836 (2012).

17. Ramarao N, Rao P Venkateduwar, Reddy G Venkat\&Gasnorkar M C, Indian J Chem, 26A: 887 (1987).

18. SantoskarRS\&BhandarkarSD,Pharmacology and Pheumacothepeutic (Popular Prakasan, Bombay), pp.648 (1993).

19. Dimmock J R, Vashishta S C \& Stables J P, Eur J Med Chem, 331: 241 (200).

20. Sogani P, Yang S, Pillette C, MureawR,Gadano, Arenwel G, Bloy C \&Lebeac D, Eur J Pharmacol, 37: 344 (1998).

21. Maurya R C, Mishra D D, Trivedi P K \& Gupta A, Synth React Inorg Met Org Chem 17: 24 (1994).

22. Rainsford K D \&Witchose M W, J Pharma Pherimacol, 28: 83 (1976).

23. Sharma R C, Parashar R K \&Mogan G, J Biol Trace Element Res, 23: 145 (1990).

24. Sharma R C\&Varshney V K, J Inorg Biochem, 228 (1991) .

25. Raman N, Kulandaisamy A \& Thangaraja $C, T$ rans Met Chem, 28: 29 (2003).

26. Rao D S \&Gonorkar M C,J Indian ChemSoc, 58: 217 (1981). 
27. Athar M,Ahmad N, Gupta A A\&Sengupta A K, Indian Drugs 225 (1985).

28. Cghoi Y K, Choi K H, Pai S M \&Dodapanenil N, J Electrochem Soc,142:4107 (1995).

29. Srivastava S K, Pandya K.P \& Nigam H L, Indian J Chem, 12: 530 (1974).

30. Ahmed, A and Akhtar F., Indian Jour. Chem. 20: 737-758 (1983).

31. Byeong-Goo J., Chae-Pyong R., Hee-Nam C, Ki-Hyung C. and Yohng-Kook C Korean chem.. Soc 17(8): 687-693 (1996) .

32. Sarika R et al. Am-Eura J Sci Res 2009; 4(4): 229-234

33. Sinn E \& Morris C M, Coordchem Rev, 4: (1969) 891.

34. Nakagawa L \&Shimanonchi T, Specrochim Acta, 20: 429 (1964).

35. Joseph J., Nagashri K., AjishaBibin Rani G., Journal of Saudi chemical society (2011).

36. Sulekh Chandra, Deepali Jain, Anjana Sarkar and Anupama J. Indian chem.. soc., 86: 220224 (2009).

37. Zahid H. Chohan and Syed K.A. Sherazi Metal based drugs, Islamic university, Bahawalpur, Pakistan Figgis BN \& Lewis J, Progs/norg chem. 6: 37 (1964) .

38. Hussain Reddy K., Radha Krishna Reddy M., and Lingappa Y., Indian Journal of chem... 35 A, 9: 775-778 (1996).

39. Bottcher A., Elias H., E-G. Jager, Langfelderova H., Mazur M., Muller L., Paulus H., Pelikan P.,
Rudolph M., Valko M., Inorg. Chem., 32: 4131 (1993).

40. Huber A., Dr. Ing. Dissertation. Technische Hochschule Darmstadt (1997).

41. Green wood N. N., Earnshaw A., Chemie der Elemente, VCH, Weinheim (1988).

42. Malik, W.U., Bembi, R. and Singh R., Trans Met. Chem.., 8: 321 (1983)

43. Vinod Kumar and Rajesh Dhakarey; Journal of the Indian council of chemistry 20(1): 46-51 (2003).

44. Z Chohan, AMunawar, C Supuran. Transition metal ion complexes of Schiff bases synthesis, characterization and antibacterial properties. Metal Based Drugs, 8: 137-143 (2001).

45. W Hanna, M Moawad. Synthesis, characterization and antimicrobial activity cobalt(II), nickel(II) and copper(II) complexes with new asymmetrical Schiff base lagands derived from 7-formyanil- substituted diaminesulphoxine and acetylacetone. Transition Metal Chem., 26(6),: 644-651 (2001).

46. J Iqbal, S Tirmizi, F Watto, M Imran. Biological Properties of Chloro-Salicylidene Aniline and its Complexes With $\mathrm{Co}(\mathrm{II})$ And $\mathrm{Cu}(\mathrm{II})$. Turk J. Biol., 30: 1-4 (2006).

47. VSingh, AKatiyar. Synthesis, characterization of some transition metal(II) complexes of acetone p-amino acetophenonesalicyloylhydrazone and their antimicrobial activity. Bio Metals, 21(4): 491-501 (2008). 